\title{
Polymerization and Copolymerization of Fumarates Containing Perfluoroalkyl Groups
}

\author{
Tsutomu Oishi, Hisaki Morikawa, and Minoru Fujimoto \\ Department of Applied Chemistry and Chemical Engineering, Faculty of Engineering, \\ Yamaguchi University, 2557 Tokiwadai, Ube 755, Japan
}

(Received June 24, 1992)

\begin{abstract}
Homopolymerizations and copolymerizations of isopropyl perfluorooctylethyl fumarate (IPFOF) and isopropyl perfluorohexylethyl fumarate (IPFHF) were performed with radical initiators in bulk and in several solvents at $50^{\circ} \mathrm{C}$ to $150^{\circ} \mathrm{C}$. The overall activation energy for the polymerization of IPFHF was $104.2 \mathrm{~kJ} \mathrm{~mol}^{-1}$. The reduced viscosities $\left(\eta_{\mathrm{sp}} / C\right)$ and glass transition points $\left(T_{\mathrm{g}}\right)$ for the polymers were $0.26 \mathrm{dl} \mathrm{g}^{-1}$ (in trifluoroacetic acid at $30^{\circ} \mathrm{C}$ ) and about $42^{\circ} \mathrm{C}$, respectively. The monomer reactivity ratios $\left(r_{1}, r_{2}\right)$ in the copolymerizations of IPFOF (or IPFHF) with styrene or methyl methacrylate, and Alfrey-Price $Q, e$ values were determined. Some of the copolymers contained about $10.0 \mathrm{dlg}^{-1}$ of $\eta_{\mathrm{sp}} / C$ and about $70^{\circ} \mathrm{C}$ of $T_{\mathrm{g}}$.

KEY WORDS Isopropyl Fluoroalkyl Fumarate / Radical Polymerization / Styrene / Methyl Methacrylate / Monomer Reactivity Ratio / Q,e Values /
\end{abstract}

There have been many reports ${ }^{1-6}$ on polymerizations and copolymerizations of dialkyl fumarates (DRF) so far. DRF's bearing branched alkyl groups are easily polymerized with radical initiators, even though DRF is one of 1,2-disubstituted ethylene type monomers. ${ }^{1}$ Polymerizabilities of dimethyl (DMF), diethyl (DEF), diisopropyl (DIPF), and di-t-butyl (DtBF) fumarates were as follows: DtBF $>$ DIPF $>$ DEF $>$ DMF. $^{2}$ Molecular structures, thermostabilities, and other physical properties for the DRF homopolymers are influenced by side ester substituents. The homopolymer composed of branched dialkyl substituent consists of a structure called "rod-like". ${ }^{3}$ The homopolymer composed of non-branched dialkyl long chains such as dihexadecyl or dioctadecyl groups, has a structure called "comb-like". ${ }^{4}$ Each rod-like or comb-like poly(DRF) has characteristic properties. Some DRF polymer films possess the properties of gas permselectivity. ${ }^{5}$ On the other hand, it has been reported that poly(DRF)s bearing both a branched alkyl and a perfluoroalkyl groups in the side substituents are very useful for oxygen-permselective membranes ${ }^{6}$ and resins having a low refractive index. ${ }^{5}$ However, no polymerization reactivities of the DRF containing both a fluoroalkyl group and a branched alkyl group have been investigated in detail.

In this article we describe the radical polymerizations of isopropyl perfluorooctylethyl fumarate (IPFOF) and isopropyl perfluorohexylethyl fumarate (IPFHF), and radical copolymerizations of IPFOF/IPFHF with styrene (ST) or methyl methacrylate (MMA). The characterization of the polymers and copolymers is also discussed, as compared with the DRF containing no perfluoroalkyl groups.

\section{EXPERIMENTAL}

\section{Synthesis of IPFOF Monomer}

IPFOF and IPFHF were prepared from maleic anhydride, thionyl chloride, isopropanol, and corresponding to perfluoroalkyl 


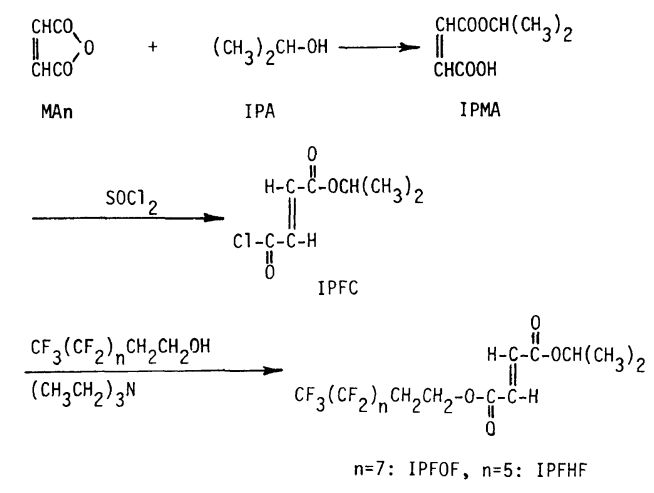

Scheme 1.

alcohol, as shown in Scheme 1.

Isopropyl fumaroyl chloride (IPFC): A mixture of maleic anhydride $(10.0 \mathrm{~g} ; 0.102 \mathrm{~mol})$ and isopropanol $(6.4 \mathrm{~g} ; 0.107 \mathrm{~mol})$ was stirred at $50^{\circ} \mathrm{C}, 65^{\circ} \mathrm{C}, 80^{\circ} \mathrm{C}$ for each $2 \mathrm{~h}$, and finally at $90^{\circ} \mathrm{C}$ for $1 \mathrm{~h}$ to obtain monoisopropyl maleate (IPMA). Thionyl chloride was carefully added dropwise to the IPMA while the reaction mixture was maintained at about $80^{\circ} \mathrm{C}$ for $2 \mathrm{~h}$. After the reaction was completed, unreacted thionyl chloride was evaporated from the mixture to give crude IPFC, which was distilled under reduced pressure to obtain pure IPFC: bp $85-93^{\circ} \mathrm{C} / 20 \mathrm{mmHg}$.

Isopropyl perfluorooctylethyl fumarate (IPFOF): Anhydrous hexane solution of IPFC was added dropwise to an anhydrous hexane solution of perfluorooctylethyl alcohol containing triethylamine at r.t. for $2 \mathrm{~h}$ under nitrogen atmosphere. After the esterification was continued for $5 \mathrm{~h}$, the resulting triethylamonium chloride was filtered. The filtrate was washed with hot water, hydrochloric acid (pH 2), $0.05 \mathrm{~N}$ of soldium carbonate solution, and then hot water, each three times. After excess hexane was evaporated, the residue was distilled in vacuo to obtain crude IPFOF. It was distilled under reduced pressure twice to give pure IPFOF: yield $75 \%$ based on IPFC; $108-110^{\circ} \mathrm{C} / 3 \times 10^{-2} \mathrm{mmHg} .{ }^{1} \mathrm{H}$ NMR (chemical shift, $\delta$, ppm from tetramethylsilane (TMS) in deuterium chloroform $\left(\mathrm{CDCl}_{3}\right)$ : $6.89(\mathrm{~s}, 2 \mathrm{H}, \mathrm{CH}=\mathrm{CH}), 5.39-4.97(\mathrm{~m}, 1 \mathrm{H}$, $\mathrm{O}-\mathrm{CH}), 4.57\left(\mathrm{t}, J=6.1 \mathrm{~Hz}, 2 \mathrm{H}, \mathrm{O}-\mathrm{CH}_{2}\right)$, $3.03-2.06\left(\mathrm{~m}, 2 \mathrm{H}, \mathrm{CF}_{2}-\mathrm{CH}_{2}-\mathrm{C}-\mathrm{O}\right), 1.32(\mathrm{~d}$, $\left.J=7 \mathrm{~Hz}, 6 \mathrm{H},\left(\mathrm{CH}_{3}\right)_{2}\right)$.

Isopropyl perfluorohexylethyl fumarate (IP$F H F$ ): IPFHF was synthesized, according to a similar method to that of IPFOF; yield $73.8 \%$ based on IPFC; $98-99^{\circ} \mathrm{C} / 1.1 \times 10^{-2} \mathrm{mmHg}$. ${ }^{1} \mathrm{H}$ NMR (chemical shift, $\delta$, ppm from TMS in $\mathrm{CDCl}_{3}: 6.81(\mathrm{~s}, 2 \mathrm{H}, \mathrm{CH}=\mathrm{CH}), 5.40-4.76$ $(\mathrm{m}, 1 \mathrm{H}, \mathrm{O}-\mathrm{CH}), 4.51(\mathrm{t}, J=6.1 \mathrm{~Hz}, 2 \mathrm{H}$, $\left.\mathrm{O}-\mathrm{CH}_{2}\right), 3.05-2.01\left(\mathrm{~m}, 2 \mathrm{H}, \mathrm{CF}_{2}-\mathrm{CH}_{2}-\mathrm{C}-\mathrm{O}\right)$, $1.27\left(\mathrm{~d}, J=7 \mathrm{~Hz}, 6 \mathrm{H},\left(\mathrm{CH}_{3}\right)_{2}\right)$.

\section{Comonomers and Other Materials}

ST and MMA were purified by the usual methods. ${ }^{7}$ Benzoyl peroxide (BPO) and azobisisobutyronitrile (AIBN) were purified with recrystallization from chloroform. 1,1-Bis $(t$ butylperoxy)-3,3,5-trimethylcyclohexane (PH3M), 2,5-dimethyl-2,5-di(t-butylperoxy)hex-3-yne (PH25B), $t$-butyl peroxypivalate (PBPV), $t$-butyl peroxyneodecanoate (PBND) and di- $t$-butyl peroxide (DBPO) supplied from Nippon Oil \& Fats Co., Ltd., were used without further purification. Solvents such as tetrahydrofuran (THF), $n$-hexane, benzene $(\mathrm{BEN})$, toluene (TOL), $o$-xylene $(o-\mathrm{X})$ were purified by distillation in the presence of sodium. Cyclohexanone (CHO), chlorobenzene (CB), o-dichlorobenzene (DCB), and methanol were purified by the usual methods. ${ }^{7}$

\section{Polymerization Procedure}

Radical bulk and solution polymerizations of IPFOF or IPFHF were carried out in a sealed glass tube with the initiator at 50 to $150^{\circ} \mathrm{C}$. After polymerization for a given time, the contents were poured into a large amount of hexane to precipitate the polymer. The polymer was filtered, purified by reprecipitation from the Freon-1,1,3 solution to hexane, and dried under reduced pressure for 2 days.

Radical copolymerizations of IPFOF (or IPFHF) with ST or MMA were performed with radical initiators $\left(1.0 \times 10^{-2} \mathrm{~mol} \mathrm{l}^{-1}\right)$ in 
bulk or in $o$-xylene $(o-\mathrm{X})$ at 50 (initiator: PBPV), 85 (BPO), 120 (DBPO), and 130 (PH3M) ${ }^{\circ} \mathrm{C}$ in a sealed tube. After the prescribed time, the contents were poured into a large amount of hexane to precipitate the copolymer. The copolymer was reprecipitated twice from the Freon-1,1,3 solution to hexane, and then filtered, dried in vacuo. The composition of the copolymer was determined from ${ }^{1} \mathrm{H}$ NMR spectra.

\section{Measurements}

$100 \mathrm{MHz}{ }^{1} \mathrm{H}$ NMR spectra for the polymers and copolymers were obtained in deuterium trifluoroacetic acid $\left(\mathrm{CF}_{3} \mathrm{COOD}\right)$ with a JEOL JNM-MH-100. Molecular weights of polymers and copolymers were measured by gel permeation chromatography (GPC) on Shimadzu LC 3A equipped with data processor, using THF as the eluent and Shimadzu polystyrene gel HGS-10-15-20-40. Diagrams of TG-DSC and X-ray diffraction were obtained with Rigaku Thermal Analysis and Shimadzu XD-3 apparatus, respectively. Reduced viscosities of the polymers were measured in trifluoroacetic acid at $30^{\circ} \mathrm{C}$. Glass transition temperature $\left(T_{\mathrm{g}}\right)$ was measured by thermal mechanical analysis (TMA) on Rigaku Thermal Analysis.

\section{RESULTS AND DISCUSSION}

\section{Homopolymerizations of IPFOF and IPFHF}

The results of radical bulk homopolymerizations of IPFOF and IPFHF are summarized in Table I. All polymerizations proceeded homogeneously throughout. The yields of polymers were much influenced by the initiators and polymerization temperatures. If the half-life of the initiator is over $10 \mathrm{~h}$ at the polymerization temperature, the yield of the polymer becomes higher. When a suitable initiator is used at the polymerization temperature, the resulting polymer yields were similar regardless of the polymerization temperature. When over $5 \%$ of the radical initiator was used, the yields of the polymers were much higher, but the reduced viscosity $\left(\eta_{\mathrm{sp}} / C\right)$ of the polymer was relatively smaller (runs 1-4 and 1-7). Generally, the reduced

Table I. Bulk polymerizations of IPFOF and IPFHF

\begin{tabular}{|c|c|c|c|c|c|c|c|}
\hline \multirow{2}{*}{ Run } & \multicolumn{2}{|c|}{ IPFOF, IPFHF } & \multirow{2}{*}{$\begin{array}{l}\text { Initiator }^{\mathrm{a}} \\
\times 10^{5} \mathrm{~mol}\end{array}$} & \multirow{2}{*}{$\begin{array}{c}\begin{array}{c}\text { Polym. } \\
\text { temp. }\end{array} \\
{ }^{\circ} \mathrm{C}\end{array}$} & \multirow{2}{*}{$\begin{array}{c}\begin{array}{c}\text { Polym. } \\
\text { time }\end{array} \\
\mathrm{h}\end{array}$} & \multirow{2}{*}{$\begin{array}{c}\text { Conversion } \\
\%\end{array}$} & \multirow{2}{*}{$\eta_{\mathrm{sp}} / C^{\mathrm{b}}$} \\
\hline & & $\times 10^{3} \mathrm{~mol}$ & & & & & \\
\hline $1-1$ & IPFOF & 3.40 & PBND(3.4) & 50 & 23 & 54.6 & 0.18 \\
\hline $1-2$ & IPFOF & 3.47 & PBPV(3.4) & 50 & 23 & 46.6 & 0.26 \\
\hline $1-3$ & IPFOF & 2.50 & $\operatorname{AIBN}(2.5)$ & 70 & 23 & 55.1 & 0.17 \\
\hline $1-4$ & IPFOF & 2.50 & $\operatorname{AIBN}(27.9)$ & 70 & 23 & 70.2 & 0.05 \\
\hline $1-5$ & IPFOF & 1.33 & $\mathrm{BPO}(2.7)$ & 120 & 23 & 49.2 & - \\
\hline $1-6$ & IPFOF & 2.51 & $\mathrm{DBPO}(2.5)$ & 120 & 23 & 67.4 & 0.06 \\
\hline $1-7$ & IPFOF & 2.74 & DBPO(11.4) & 120 & 23 & 74.2 & 0.07 \\
\hline $1-8$ & IPFOF & 1.64 & PH3M(17.4) & 130 & 23 & 9.3 & - \\
\hline $1-9$ & IPFOF & 4.79 & PH25B(5.1) & 150 & 23 & 61.1 & 0.03 \\
\hline $1-10$ & IPFHF & 4.47 & PBND(4.5) & 50 & 23 & 48.7 & 0.20 \\
\hline $1-11$ & IPFHF & 4.22 & PBPV(4.3) & 50 & 23 & 39.7 & 0.25 \\
\hline $1-12$ & IPFHF & 2.98 & AIBN(3.0) & 70 & 23 & 51.3 & 0.19 \\
\hline $1-13$ & IPFHF & 2.98 & $\mathrm{DBPO}(3.0)$ & 120 & 23 & 49.4 & 0.12 \\
\hline $1-14$ & IPFHF & 1.99 & $\mathrm{PH} 25 \mathrm{~B}(2.0)$ & 150 & 23 & 32.3 & 0.03 \\
\hline
\end{tabular}

a PBND, $t$-butyl peroxyneodecanoate; PBPV, $t$-butyl peroxy pivalate; DBPO, di- $t$-butylperoxide; PH3M, 1,1-bis( $t$-butyl peroxy)-3,3,5-trimethyl cyclohexane; PH25B, 2,5-dimethyl-2,5-di-( $t$-butylperoxy)hex-3-yne.

b $\mathrm{dl} \mathrm{g}^{-1} ; C=c a .1 .0 \mathrm{~g} \mathrm{dl}^{-1}$. 
T. Oishi, H. Morikawa, and M. Fujimoto

Table II. Radical solusion polymerization of IPFOF and IPFHF

\begin{tabular}{|c|c|c|c|c|c|c|c|c|}
\hline \multirow{2}{*}{ Run } & \multicolumn{2}{|c|}{ IPFOF, IPFHF } & \multirow{2}{*}{$\frac{\text { Initiator }}{\times 10^{5} \mathrm{~mol}}$} & \multirow{2}{*}{$\begin{array}{c}\begin{array}{c}\text { Polym. } \\
\text { solvent }^{\mathrm{a}}\end{array} \\
\mathrm{ml}\end{array}$} & \multirow{2}{*}{$\begin{array}{c}\text { Polym. } \\
\text { temp. }\end{array}$} & \multirow{2}{*}{$\begin{array}{c}\begin{array}{c}\text { Polym. } \\
\text { time }\end{array} \\
\mathrm{h}\end{array}$} & \multirow{2}{*}{$\begin{array}{c}\text { Yield } \\
\%\end{array}$} & \multirow{2}{*}{$\eta_{\mathrm{sp}} / C^{\mathrm{b}}$} \\
\hline & & $\times 10^{3} \mathrm{~mol}$ & & & & & & \\
\hline $2-1$ & IPHOF & 2.99 & PBND(3.0) & BEN(1) & 50 & 23 & 56.4 & 0.11 \\
\hline $2-2$ & IPFOF & 2.48 & $\operatorname{AIBN}(2.5)$ & BEN(1) & 70 & 23 & 37.7 & 0.09 \\
\hline $2-3$ & IPFOF & 2.52 & $\operatorname{AIBN}(9.1)$ & $o-\mathrm{X}(1)$ & 70 & 23 & 19.8 & 0.03 \\
\hline $2-4$ & IPFOF & 2.52 & $\operatorname{AIBN}(9.2)$ & $\mathrm{DCB}(1)$ & 70 & 23 & 47.9 & 0.06 \\
\hline $2-5$ & IPFOF & 1.68 & $\mathrm{BPO}(4.4)$ & $o-\mathrm{X}(1)$ & 110 & 23 & 1.2 & - \\
\hline $2-6$ & IPFOF & 2.09 & $\mathrm{DBPO}(8.8)$ & $o-\mathrm{X}(1)$ & 120 & 23 & 11.1 & 0.03 \\
\hline $2-7$ & IPFOF & 2.11 & DBPO(8.6) & $\operatorname{DCB}(1)$ & 120 & 23 & 42.3 & 0.04 \\
\hline $2-8$ & IPFOF & 3.30 & PH25B(6.9) & $\operatorname{DCB}(2)$ & 150 & 23 & 17.8 & 0.03 \\
\hline $2-9$ & IPFHF & 2.98 & $\operatorname{PBND}(3.0)$ & BEN(1) & 50 & 23 & 47.7 & 0.13 \\
\hline $2-10$ & IPFHF & 2.98 & AIBN(3.0) & BEN(1) & 70 & 23 & 36.8 & 0.11 \\
\hline $2-11$ & IPFHF & 2.05 & $\operatorname{AIBN}(2.0)$ & $\operatorname{DCB}(1)$ & 70 & 23 & 15.0 & - \\
\hline $2-12$ & IPFHF & 2.00 & $\operatorname{DBPO}(2.0)$ & $\operatorname{DCB}(1)$ & 120 & 23 & 22.4 & - \\
\hline $2-13$ & IPFHF & 1.99 & $\mathrm{PH} 25 \mathrm{~B}(2.0)$ & $\operatorname{DCB}(1)$ & 150 & 23 & 4.7 & - \\
\hline
\end{tabular}

a $o$-X, $o$-xylene; DCB, dichlorobenzene; BEN, benzene.

b $\mathrm{dl} \mathrm{g}^{-1} ; C=c a .1 .0 \mathrm{~g} \mathrm{dl}^{-1}$.

viscosities of the polymers obtained at high temperatures were relatively low $(0.12$ to 0.03). When the PBND and PBPV, liquid initiators, were used at about $50^{\circ} \mathrm{C}$, the reduced viscosities were $0.18-0.26 \mathrm{dl} \mathrm{g}^{-1}$.

The results of solution polymerizations of IPFOF and IPFHF are summarized in Table II. Generally, the yields and the reduced viscosities of the polymers obtained in solution polymerizations were lower than those in bulk polymerizations. Figure 1 shows the relationship between yields of the polymers and dielectric constants $\left(\varepsilon_{\mathrm{r}}\right)$ of the solvents. The monomer and initiator concentrations were about $2.0 \times 10^{-3} \mathrm{~mol}^{-1}$ and $2.0 \times$ $10^{-5} \mathrm{~mol}^{-1}$, respectively. In the polymerizations of IPFOF and IPFHF initiated with PBND at $50^{\circ} \mathrm{C}$, the yield in benzene was best, and decreased with increase of dielectric constants of the solvents except for toluene and $o$-xylene. The yields in toluene and $o$ xylene were much lower than in benzene, which suggests that the yield is associated with a structure of the aromatic solvent. In the polymerization of IPFOF and IPFHF initiated with AIBN at $70^{\circ} \mathrm{C}$, similar tenden- cies were observed. In the polymerization initiated with $\mathrm{DBPO}$ at $120^{\circ} \mathrm{C}$, the yield in DCB was the best. It is interesting to note that remarkable solvent effects on the yields of the polymers were detected in radical polymerizations, as described above. It is difficult to explain the reason clearly. The reason may be chracteristic perfluoroalkyl groups in the esters. It seems that perfluorooctylethyl and perfluorohexylethyl groups are long linear and rigid side chains, as described later.

In the ${ }^{1} \mathrm{H}$ NMR spectra of the poly(IPFOF) and poly(IPFHF), the signal assigned to the double bond of the monomer disappeared and other significant peaks could not be observed. Thus, an ordinary addition polymerization involving double bonds may take place.

Common dialkyl fumarates; especially of diisopropyl or di-t-butyl fumarates, contain high polymerizability and the reduced viscosities of the polymers were 0.5 to $1.14 \mathrm{dl} \mathrm{g}^{-1}$, as reported previously. ${ }^{1}$ The number-average molecular weight of poly(didodecyl fumarate) which contains long linear chains, was $1.05 \times$ $10^{4}$ and polymerizability was relatively low. ${ }^{4}$ Thus, a linear long side chain may make 


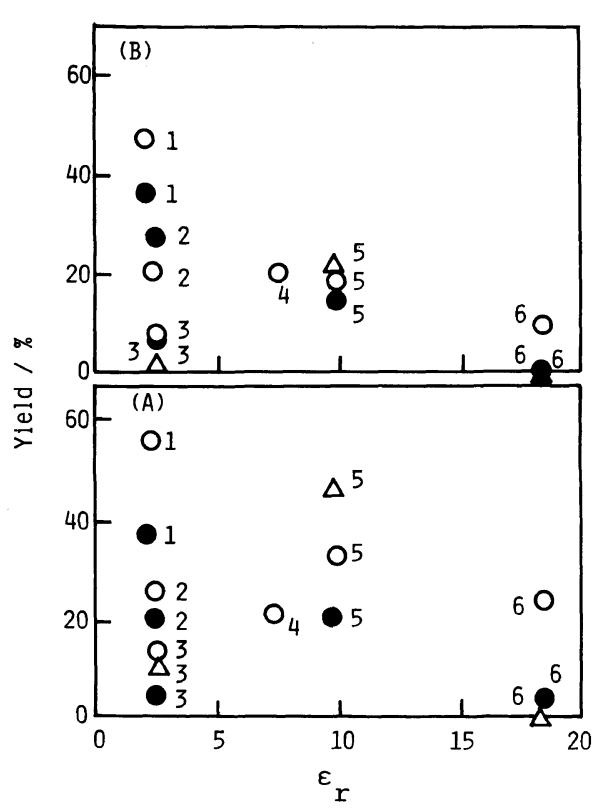

Figure 1. Relationships between yields of polymers and dielectric constants $\left(\varepsilon_{\mathrm{r}}\right)$ of the solvents: (1) BEN, (2) TOL, (3) $o-\mathrm{X}$, (4) THF, (5) DCB, and (6) CHO: (A) [IPFOF] $=$ $2.0 \times 10^{-3} \mathrm{~mol} \mathrm{l}^{-1}$; [initiator] $=2.0 \times 10^{-5} \mathrm{~mol} \mathrm{l}^{-1}$, (B) $[\mathrm{IPFHF}]=2.0 \times 10^{-3} \mathrm{~mol} \mathrm{1}{ }^{-1}$; [initiator $]=2.0 \times$ $10^{-5} \mathrm{~mol} \mathrm{l}^{-1}$; (○) $50^{\circ} \mathrm{C},(\bigcirc) 70^{\circ} \mathrm{C}$, and $(\triangle) 120^{\circ} \mathrm{C}$.

the polymerizabilities of IPFOF and IPFHF lower. A more important factor of the lower polymerizabilities may be a characteristic perfluoroalkyl group. That is, the molecular chains of perfluorooctylethyl and perfluorohexylethyl groups were thought to be more rigid because of repulsion of fluoride itself. ${ }^{8}$ Accordingly, considerably low polymerizabilities of IPFOF and IPFHF may be attributable to a long linear and rigid chain of the ester group i.e., perfluoro alkyl group.

To estimate the overall activation energy (E) for the polymerization of IPFHF, the polymerizations were carried out with a constant IPFHF monomer $\left(0.79 \mathrm{~mol} \mathrm{l}^{-1}\right)$ and AIBN concentration $\left(1.0 \times 10^{-2} \mathrm{moll}^{-1}\right)$ in benzene at $50,60,70$, and $80^{\circ} \mathrm{C}$. Timeconversion curves were drawn on the basis of the results. From the slope of each curve, the initial rate of polymerization $\left(R_{\mathrm{p}}\right)$ could be calculated. Figure 2 shows relationship be-

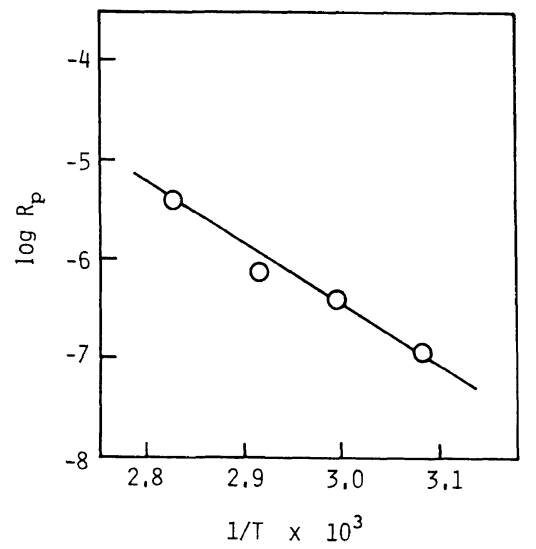

Figure 2. Arrhenius plots for $\log R_{\mathrm{p}}$ with $1 / T$ for solution polymerization of IPFHF initiated by AIBN in benzene.

tween $\log R_{\mathrm{p}}$ and $1 / T$. The overall activation energy $(E)$ of the polymerization was obtained as $104.2 \mathrm{~kJ} \mathrm{~mol}^{-1}$. This value was slightly higher than those reported for diethyl fumarate (DEF) $\left[\left(89 \pm 2 \mathrm{~kJ} \mathrm{~mol}^{-1}\right)^{9} ;\left(90.6 \mathrm{~kJ} \mathrm{~mol}^{-1}\right)^{10}\right]$ and diisopropyl fumarate (DIPF) $(92.9 \mathrm{~kJ}$ $\left.\mathrm{mol}^{-1}\right){ }^{3}$ The $R_{\mathrm{p}}$ of IPFHF is about $1 / 100$ times that of the DIPF. ${ }^{3}$ These may result from a long linear and very rigid side chain, i.e., the perfluoroethyl group.

\section{Radical Copolymerizations}

Copolymerizations of IPFOF $\left(\mathrm{M}_{1}\right)$ [or IPFHF $\left.\left(M_{1}\right)\right]$ with ST $\left(M_{2}\right)$ or MMA $\left(M_{2}\right)$ were performed in bulk and in solvents at 50 to $130^{\circ} \mathrm{C}$ by using radical initiators, i.e., PBPV $\left(50^{\circ} \mathrm{C}\right)$, BPO $\left(85^{\circ} \mathrm{C}\right)$, DBPO $\left(120^{\circ} \mathrm{C}\right)$, and $\mathrm{PH} 3 \mathrm{M}\left(130^{\circ} \mathrm{C}\right)$. To obtain a suitable halflife period of the initiator, the polymerization temperatures were varied. The bulk copolymerizations proceeded homogeneously throughout. In the solution copolymerization, however, part of the polymer precipitated in the solvent. The resulting copolymers except for some of poly(IPFOF-co-ST) and poly(IPFHF$c o-\mathrm{ST}$ ) were insoluble in ordinary organic solvents and soluble only in trifluoroacetic acid and Freon-1,1,3. The yields of copolymers were 5 to $30 \%$ for 15 to $23 \mathrm{~h}$. The yields 
in the bulk copolymerizations were about three times as high as those in the solution polymerizations.

Typical copolymer-composition curves are shown in Figure 3. In general, the copolymerizabilities of IPFOF or IPFHF with ST were

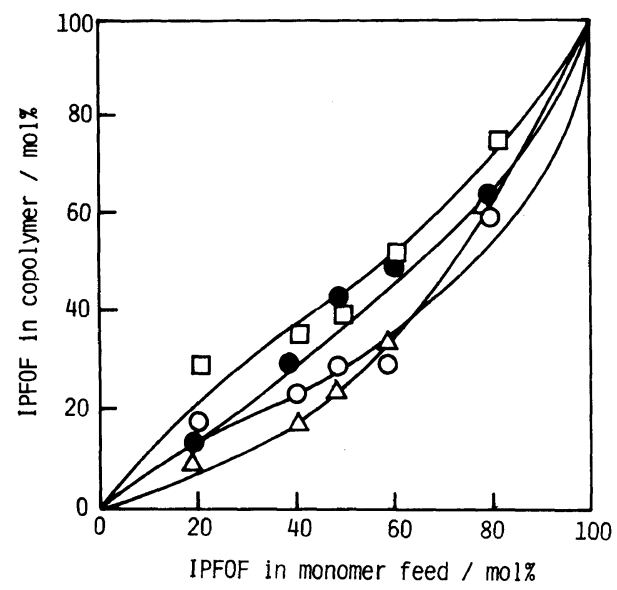

Figure 3. Copolymer-composition curves for (O) IPFOF-MMA initiated by PBPV in bulk at $50^{\circ} \mathrm{C}$, (O) IPFOF-MMA initiated by BPO in bulk at $85^{\circ} \mathrm{C},(\triangle)$ IPFOF-MMA initiated by BPO in $o$-X at $85^{\circ} \mathrm{C}$, and ( $\square$ ) IPFOF-MMA initiated by DBPO in bulk at $120^{\circ} \mathrm{C}$. better than those of IPFOF or IPFHF with MMA.

The monomer reactivity ratios $\left(r_{1}, r_{2}\right)$ were calculated from the High-Conversion method reported by Tüdös and co-workers ${ }^{11}$ and from the Integration method by Mayo and Lewis. ${ }^{12}$ From these $r_{1}$ and $r_{2}$ values, AlfreyPrice $^{13} Q$ and $e$ values are determined. These copolymerization parameters are shown in Table III. $Q$ and $e$ values in the copolymerization at relatively high temperatures (120 and $130^{\circ} \mathrm{C}$ ) were abnormal. Except for the values, differences between IPFOF and IPFHF could not be detected. Compared with $Q$ and $e$ reported previously, ${ }^{3,14,15}$ as shown in Table III, $Q$ of the IPFOF and IPFHF are between the value of DMF (or DME) and DIPF. The $e$ values of IPFOF and IPFHF are similar to those reported for DMF and DEF. $Q$ and $e$ for the IPFOF and IPFHF indicate that both IPFOF and IPFHF are electron-accepting conjugative monomers.

$\mathrm{X}$-ray diffraction (XRD) diagrams for the poly(IPFOF) (run 1-4), poly(IPFOF-co-MMA) and poly(IPFOF-co-ST) obtained in bulk

Table III. Copolymerization parameters

\begin{tabular}{|c|c|c|c|c|c|c|c|}
\hline$M_{1}$ & $\mathrm{M}_{2}$ & Sol. $^{a}$ & $\frac{\text { Temp. }}{{ }^{\circ} \mathrm{C}}$ & $r_{1}$ & $r_{2}$ & $Q_{1}$ & $e_{1}$ \\
\hline IPFOF & ST & None & 85 & 0.52 & 0.28 & 1.18 & 0.59 \\
\hline IPFOF & ST & $o-\mathrm{X}$ & 85 & 0.10 & 0.23 & 0.93 & 1.15 \\
\hline IPFOF & ST & $o-\mathrm{X}$ & 130 & 0.20 & 0.09 & 2.23 & 1.20 \\
\hline IPFOF & MMA & None & 50 & 0.06 & 1.02 & 1.43 & 2.10 \\
\hline IPFOF & MMA & None & 85 & 0.14 & 2.05 & 0.56 & 1.50 \\
\hline IPFOF & MMA & None & 120 & 0.32 & 0.41 & 3.16 & 1.82 \\
\hline IPFOF & MMA & $o-\mathrm{X}$ & 85 & 0.15 & 3.38 & 0.30 & 1.21 \\
\hline IPFOF & MMA & $o-\mathrm{X}$ & 130 & 0.08 & 10.8 & 0.08 & 0.82 \\
\hline IPFHF & MMA & None & 50 & 0.04 & 1.39 & 1.06 & 2.12 \\
\hline IPFHF & MMA & None & 120 & 0.14 & 1.29 & 0.97 & 1.70 \\
\hline IPFHF & ST & None & 50 & 0.23 & 0.95 & 0.39 & 0.43 \\
\hline $\mathrm{DMF}^{\mathrm{b}}$ & ST & None & 90 & 0.03 & 0.39 & 0.48 & 1.31 \\
\hline $\mathrm{DEF}^{\mathrm{c}}$ & - & - & - & - & - & 0.29 & 2.26 \\
\hline DIPF $^{d}$ & VAC & Ben & 60 & 0.90 & 0.012 & 1.37 & 1.91 \\
\hline
\end{tabular}

\footnotetext{
a Polymerization solvent: $o$-X, $o$-Xylene.

b dimethyl fumarate: see ref 14 .

c diethyl fumarate: see ref 15 .

d diisopropyl fumarate: see ref 3 .
} 


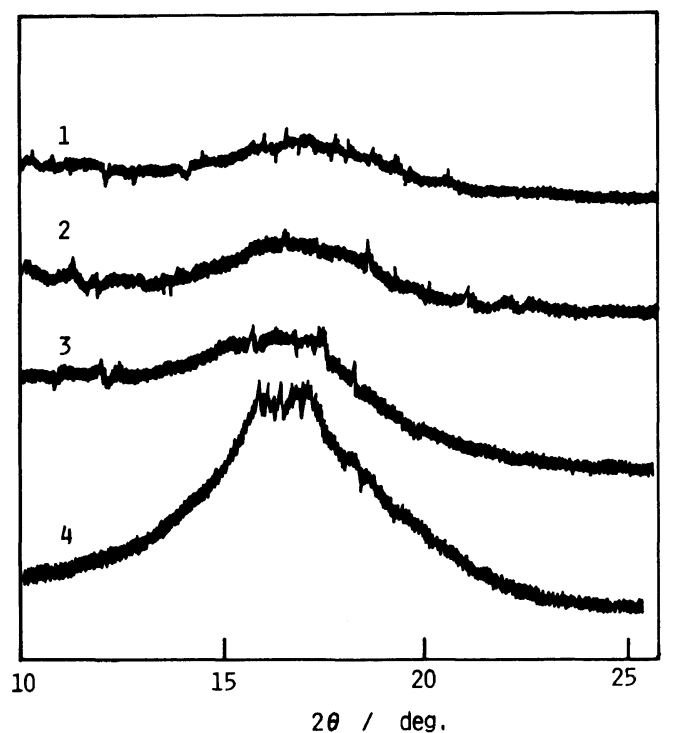

Figure 4. X-Ray diffraction diagrams for (1) poly(IPFOF) powder [run 1-7], (2) poly(IPFOF) film [run 1-7], (3) poly(IPFOF-co-MMA) [in bulk; BPO; $85^{\circ} \mathrm{C}$; IPFOF $/ \mathrm{MMA}=1$ in feed], and (4) poly(IPFOF-co-ST) [in bulk; $\mathrm{BPO} ; 85^{\circ} \mathrm{C}$; IPFOF $/ \mathrm{ST}=1$ in feed].

polymerizations are shown in Figure 4. One broad peak was observed at about $2=17 \mathrm{deg}$. XRD for the poly(IPFHF) (run 1-12) was similar to that of poly(IPFOF), and both polymers were found to be slightly crystalline but almost amorphous. There have been reports ${ }^{4}$ on the crystallization of side groups in fumarates containing linear long chain side groups such as poly(didodecyl fumarate) and poly(dioctadecyl fumarate). Judging from the report, in the poly(IPFOF) and poly(IPFHF), neither the number of carbons nor flexibility of the side group is enough because of rigid perfluoroalkyl groups.

Diagrams of a thermogravimetric (TG) and a differential scanning calorimetric (DSC) analysis for the poly(IPFOF), poly(IPFOFco-ST), and poly(IPFOF-co-MMA) are shown in Figure 5. TG-DSC curves for the IPFHF polymers and copolymers indicated similar patterns to those for IPFOF polymer and copolymers. In all TG-DSC curves, only one endothermal peak was observed due to

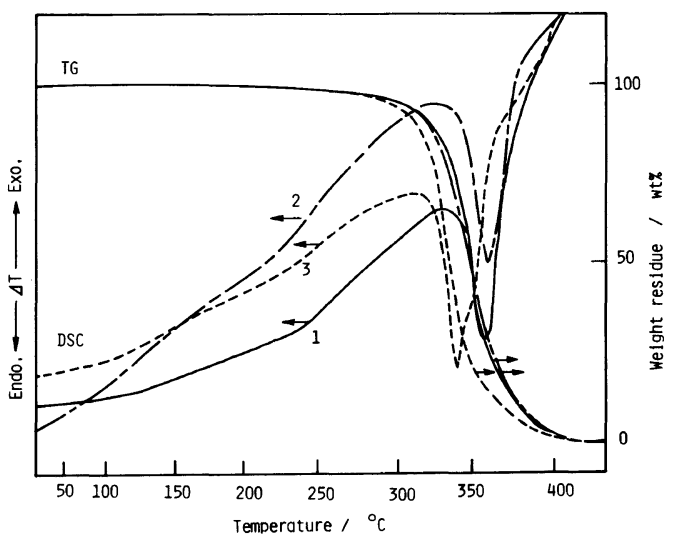

Figure 5. TG-DSC curves for (1) poly(IPFOF) [run 1-4], (2) poly(IPFOF-co-ST) obtained with BPO in bulk at $85^{\circ} \mathrm{C}$ (IPFOF/ST $=1$ in feed), and (3) poly(IPFOF-coMMA) obtained with $\mathrm{BPO}$ in bulk at $85^{\circ} \mathrm{C}$ (IPFOF/ $\mathrm{MMA}=1$ in feed) at a heating rate of $10^{\circ} \mathrm{C} \mathrm{min}^{-1}$ in nitrogen.

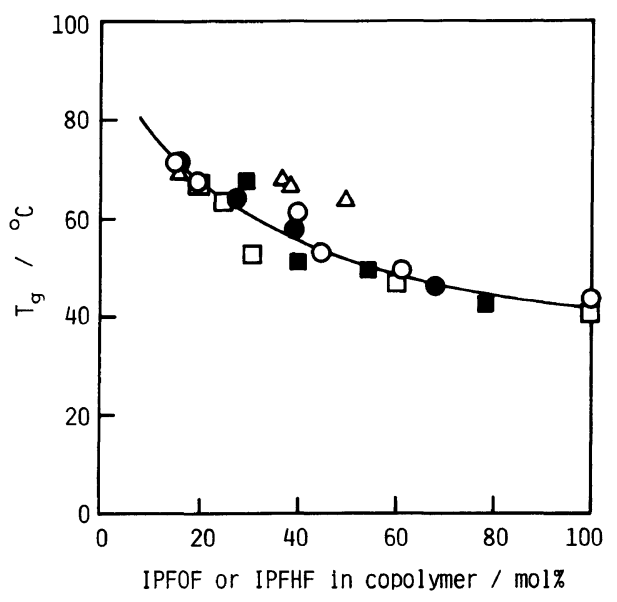

Figure 6. Relationship between glass transition temperature $\left(T_{\mathrm{g}}\right)$ and compositions of the copolymers: $(\square)$ poly(IPFOF-co-MMA) initiated by PBPV in bulk at $50^{\circ} \mathrm{C}$, ( $)$ poly(IPFOF-co-MMA) initiated by DBPO in bulk at $120^{\circ} \mathrm{C},(\mathrm{O})$ poly(IPFHF-co-MMA) initiated by PBPV in bulk at $50^{\circ} \mathrm{C}$, (O) poly(IPFHF-co-MMA) initiated by $\mathrm{DBPO}$ in bulk at $120^{\circ} \mathrm{C} ;(\triangle)$ poly(IPFHFco-ST) initiated by PBPV in bulk at $50^{\circ} \mathrm{C}$.

degradation of the IPFOF unit. There were no softening points $\left(T_{\mathrm{m}}\right)$ for poly(IPFOF) and poly(IPFHF). The initial degradation temperatures $\left(T_{\mathrm{d}}\right)$, which mean the beginning of weight loss of the polymer, were observed at 


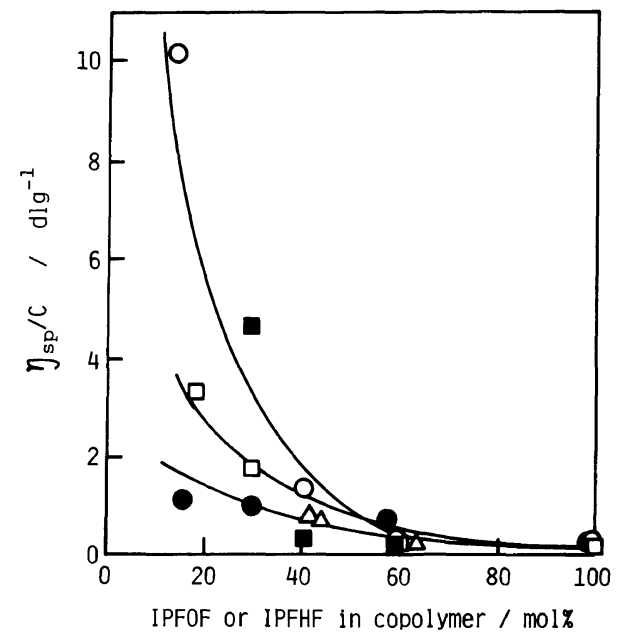

Figure 7. Relationship between reduced viscosities $\left(\eta_{\mathrm{sp}} / C\right)$ and composition of the copolymers: The same samples as in Figure 6.

\section{8 to $275^{\circ} \mathrm{C}$.}

Glass transition temperatures $\left(T_{\mathrm{g}}\right)$ of the polymers were measured with thermal mechanical analysis (TMA). Relationships between $T_{\mathrm{g}} \mathrm{s}$ and the composition of the copolymers are shown in Figure 6. In both IPFOF and IPFHF systems, $T_{\mathrm{g}} \mathrm{s}$ slightly decreased with the contents of IPFHF or IPFOF in the copolymers. It was reported ${ }^{16}$ that no $T_{\mathrm{g}} \mathrm{s}$ of the poly(DIPF) could be observed under degradation temperature of the polymers.

The reduced viscosities $\left(\eta_{\mathrm{sp}} / C\right)$ of some of the poly(IPFOF-co-MMA)s and poly(IPFHFco-MMA)s resulted in bulk were abnormally high, as shown in Figure 7, and decreased with increase of the IPFOF or IPFHF content in the copolymers. $\eta_{\mathrm{sp}} / C(=0.05$ to 0.18$)$ of the poly(IPFOF- $-\mathrm{o}$-ST)s and poly(IPFHF-coST)s were generally lower than those of poly(IPFOF-co-MMA)s and poly(IPFHF-coMMA)s. The molecular weights of the poly(IPFOF-co-ST)s having $\eta_{\text {sp }} / C$ of 0.11 and 0.18 were found to be in agreement with $1.9 \times 10^{4}$ and $3.4 \times 10^{4}$, respectively, by GPC measure- ments. Other polymers and copolymers were insoluble in general organic solvents.

Acknowledgments. We are indebted to Mr. M. Momoi for carrying out the elemental analysis and to Mr. K. Katoh in Nippon Oil \& Fats Co., Ltd., for supplying the radical initiators and part of the IPFOF monomer.

\section{REFERENCES}

1. T. Otsu, O. Ito, N. Toyoda, and S. Mori, Makromol. Chem., Rapid Commun., 2, 735 (1981).

2. T. Otsu, H. Minami, and N. Toyoda, Polym. Bull., 11, 453 (1984).

3. T. Otsu, H. Minami, N. Toyoda, and T. Yasuhara, Makromol. Chem., Suppl., 12, 133 (1985).

4. T. Hirabayashi and K. Yokoya, Polym. J., 19, 1115 (1987).

5. T. Otsu, N. Amaya, and T. Murata, Jpn. Kokai Tokkyo Koho, JP 62-204824 (1987).

6. Y. Hashimoto, T. Umaba, and M. Kamei, Eur. Patent Appl. EP 234, 605 (1987).

7. J. A. Riddick, W. B. Bunger, and T. K. Sakano, "Organic Solvents," 4th ed., John Wiley \& Sons, Inc., New York, 1986; T. Otsu and M. Kinoshita, "Kobunshi Gousei no Jikkennhou," Kagaku Dojin, Kyoto, 1972, pp 69-91.

8. K. Ihara and S. Koujiya, "Fussokei Polymer," Kyoritsu Syuppan, 1990, Tokyo.

9. W. I. Bengough, G. B. Park, and R. A. Young, Eur, Polym. J., 11, 305 (1981).

10. T. Otsu and T. Ishikawa, Polym. Prepr., Jpn., 28, 814 (1979).

11. F. Tüdös, T. Kelen, T. Foldes-Berezsnich, and B. Turcsanyi, J. Macromol. Sci.-Chem., A10, 1513 (1976).

12. F. R. Mayo and F. M. Lewis, J. Am. Chem. Soc., 66, 1594 (1944).

13. T. Alfrey, Jr. and C. C. Price, J. Polym. Sci., 2, 101 (1947).

14. T. Otsu, O. Ito, N. Toyoda, and S. Mori, Mem. Fac. Eng., Osaka City Univ., 22, 129 (1981).

15. R. Z. Greenley, in "Polymer Handbook," J. Brandrup and E. H. Immergut, Ed., WileyInterscience Publishes, New York, N.Y., 1989, p II-268.

16. T. Otsu, T. Yasuhara, and A. Matsumoto, $J$. Macromol. Sci., A25, 537 (1988). 